\title{
The Relation of Weight Loss with Hyperinflation, Serum Adiponectin, Ghrelin and Leptin Levels in Chronic Obstructive Pulmonary Disease
}

\author{
Özlem Cingözler'1, Cengiz Özge², Lülüfer Tamer³ , Hatice Yıldırım³, \\ Bahar Taşdelen ${ }^{4}$, Eylem Sercan Özgür², Sibel Atış Nayc² ${ }^{2}$ Ahmet İlvan² \\ ${ }^{1}$ Clinic of Chest Diseases, Mersin Tarsus State Hospital, Mersin \\ ${ }^{2}$ Department of Chest Diseases, Mersin University Faculty of Medicine, Mersin \\ ${ }^{3}$ Department of Biochemistry, Mersin University Faculty of Medicine, Mersin \\ ${ }^{4}$ Department of Biostatistics, Mersin University Faculty of Medicine, Mersin
}

\begin{abstract}
Objective: Although protein-calorie malnutrition and associated weight loss have been demonstrated in chronic obstructive pulmonary disease (COPD), the reasons for weight loss, as well as the relation of weight loss with hormonal and inflammatory markers is not clear. Therefore, the present study aimed to investigate the reasons for weight loss in COPD patients and the relation of weight loss with hormonal/inflammatory markers and hyperinflation.

Methods: The present study included 60 patients with stable COPD who were admitted to the Chest Diseases Outpatient Clinic and 20 healthy controls. The patients were divided into three groups according to their body mass index (BMI); Group 1: BMI <20 kg/m², Group 2: BMI $20-25 \mathrm{~kg} / \mathrm{m}^{2}$ and Group 3: BMI $>25 \mathrm{~kg} / \mathrm{m}^{2}$. The patients underwent pulmonary function testing and arterial blood gas analysis. Serum adiponectin, ghrelin, leptin, tumour necrosis factor (TNF) alpha, C-reactive protein (CRP), prealbumin and transferrin levels were measured. The results were evaluated by appropriate statistical methods.

Results: Considering the patient groups together, leptin and ghrelin levels were found to be statistically significantly lower in the patient group ( $p=0.001$ and $p=0.003$ ). Serum leptin level was found to be lower in Group 1 with a BMI $<20$ as compared to the other COPD patients and the control group $(\mathrm{p}<0.001)$. Adiponectin level was lower in the group with a BMI $<20$ as compared to the group with a BMI $>25$ $(\mathrm{p}=0.031)$. No statistically significant difference was determined between the patients with and without hyperinflation in terms of serum ghrelin, leptin, adiponectin, TNF- $\alpha$, prealbumin and transferrin levels.
\end{abstract}

Conclusion: Decreased serum ghrelin and leptin levels were associated with weight loss. However, no relation could be identified between hyperinflation and hormonal markers. It was thought that further studies are needed in order to reach a definite conclusion.

Keywords: Adiponectin, ghrelin, COPD, leptin, body mass index

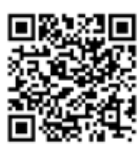

Received date: 26.08 .2013 Accepted date: 24.10 .2013

Address for correspondence Eylem Sercan Özgür, Department of Chest Diseases, Mersin University Faculty of Medicine, Mersin, Turkey

E-mail: eylemozgur@yahoo.com

(C) Copyright 2014 Turkish Respiratory Society (TRS) DOI: 10.5152/ejp.2014.71245

- Available online at www.eurasianjpulmonol.com

\section{INTRODUCTION}

Chronic obstructive pulmonary disease (COPD) is a progressive and inflammatory disease characterized by chronic airway limitation. While, attention was paid on airflow limitation in the previous years, today systemic inflammatory component of the disease is in the fore front. The main change in the concept, concerning the definition of this disease, in time is the understanding that COPD is not only a disease limited to the lungs but is also a systemic inflammatory disease (1-3).

Despite various hypotheses on how and why systemic inflammation occurs in COPD, it has not been completely clarified. However, whatever the mechanism is, studies demonstrated that systemic inflammation in COPD might lead to various comorbidities such as change in body composition, osteoporosis, cardiovascular system diseases and diabetes mellitus (2-5). 
Changes in body composition (lean body mass, fat mass and bone mineral density), which is considered as an important comorbidity, can also be seen in COPD patients without clinically significant weight loss $(6,7)$. Although the reasons for body composition changes are not clear, increase in energy consumption associated with respiration and negative energy balance caused by impaired metabolic and functional capacity, which develop in line with increase in respiratory work, are used to explain this change (8).

In the literature, studies on systemic inflammation and body composition changes in COPD have investigated numerous inflammatory markers but a definite judgment could not be made $(3,4,9)$. The aim of the present study is to try to provide a better understanding of the reasons for weight loss, which unfavourably influences the prognosis of the patients, by investigating the relation of body composition changes in patients with stable severe COPD with leptin, adiponectin, ghrelin, tumour necrosis factor (TNF)-alpha levels and pulmonary functions.

\section{METHODS}

The study was approved by the Local Ethics Committee with the decision dated 04.06.2008 and no. 2008/58. All patients included in the study were informed prior to the study and their consents were obtained.

The study included 60 COPD patients, who have been receiving optimum medical treatment for at least 2 years and had stable disease for 6 weeks, and were admitted to the Chest Diseases Outpatient Clinic between May and September 2009, and 20 healthy controls. The diagnosis of COPD was made based on the GOLD 2009 criteria (post bronchodilator $\mathrm{FEV}_{1} / \mathrm{FVC}<70 \%$ and $\mathrm{FEV}_{1}<80 \%$ ) and patients with severe COPD were identified based on the same criteria $\left(\mathrm{FEV}_{1}<50 \%\right)$. Detailed anamnesis was taken from all participants and physical examination was performed.

Patients with one of the following conditions were excluded: 1) Receiving nutritional support, 2) Receiving oral or inhaled corticosteroid therapy, 3) Having comorbidities such as diabetes, hyperthyroidism, hypothyroidism, chronic renal insufficiency, rheumatoid arthritis, and systemic lupus erythematous that may intervene with the outcomes, 4) Having lower respiratory tract infection or COPD attack in the last 6 weeks.

\section{Pulmonary Function Tests}

Spirometric tests and lung volume measurements of all subjects were done in accordance with the criteria recommended by the European Respiratory Society using a computer-assisted spirometry (Vmax22D, Sensor Medics, California, USA). FVC, FEV , and FEV $_{1} /$ FVC ratio were measured and the absolute values and the percentage of expected values of these parameters were analysed. Lung volumes of the patients were measured by multiple-breath nitrogen washout method. A FRC higher than $120 \%$ was considered as hyperinflation (10). Arterial blood gas analysis (cobas b 121, Roche, Mannheim, Germany) was performed on blood samples taken from the radial arteries of the patients, and $\mathrm{pH}$, partial arterial carbon dioxide pressure $\left(\mathrm{PaCO}_{2}\right)$, partial arterial oxygen pressure $\left(\mathrm{PaO}_{2}\right)$, bicarbonate $\left(\mathrm{HCO}_{3}\right)$ and oxygen saturation parameters were assessed.

\section{Anthropometric Measurements}

With regard to anthropometric measurements, height and weight of the subjects were measured by the same person while the pa- tients were in standing position with empty stomach using standard measuring instruments. Lean body mass (LBM) and fat mass (FM) were measured by single-frequency $(50 \mathrm{kHz})$ bioelectric impedance analyser (Body Fat Analyser, model TBF 300, Tanita, Tokyo, Japan). Body mass index (BMI) was calculated using Quetelet index, dividing the patient's weight by square meter of the patient's height (weight/height ${ }^{2}$ ) and presented as $\mathrm{kg} / \mathrm{m}^{2}$. The patients were divided into three groups according to BMI (Group $1 \mathrm{BMI}<20$; Group $2 \mathrm{BMI}=$ 20-25; Group 3 BMI >25).

\section{Biochemical Analysis}

Blood samples were taken between 08.00 and 09.00 in the morning after 12-hour fasting. TNF-alpha, leptin, adiponectin, and ghrelin concentrations were studied by ELISA (Enzyme-Linked Immunosorbent Assay, Organon Teknika, Durham NC, USA) device. Prealbumin and transferrin levels were studied by immunoturbidimetric method in cobas 501 (Roche Diagnostics, GmbH, Roche, Mannheim, Germany) autoanalyzer.

\section{Statistical Analysis}

For the analysis of continuous variables, data were tested for normal distribution and it was observed that the variables were not distributed normally. Therefore, nonparametric methods were used for statistical analysis. Whilst paired group comparison was done by Mann-Whitney $U$ test, comparison of more than two groups was done by Kruskal-Wallis $\mathrm{H}$ test. Dunn's post-hoc test was used to determine the group which caused the difference. Correlation between variables was investigated by calculating Spearman's Rho coefficient. Statistical analysis was done using SPSS v. 11.5.1 and STATISTICA v. 6.1 package program. In statistical analysis, difference with a $p<0.05$ was considered significant.

\section{RESULTS}

Demographic and functional characteristics of the patient and control groups are presented in Table 1.

Biochemical and endocrine parameters of COPD patients that were divided into three groups (BMI <20, BMI: 20-25 and BMI >25) and comparison of these parameters according to body mass index are demonstrated in Table 2.

Leptin levels were significantly lower in COPD patients as compared to the control group ( $p=0.001$ ) (Table 1$)$. In subgroup analysis, leptin levels were found to be significantly lower in COPD patients with a $\mathrm{BMI}<20$ as compared to the other COPD patients and the control group $(p<0.001)$. Correlation analysis revealed a positive correlation between serum leptin levels and BMI $(r=0.522$ and $p=0.0001)$ and lean body mass $(r=0.408$ and $p=0.001)$.

Whilst there was no difference between overall patient groups and the control group in terms of adiponectin levels, it was observed that adiponectin levels were statistically significantly lower in the group with a $\mathrm{BMI}<20$ as compared to the group with a BMI $>25(p=0.031)$. Serum adiponectin levels were positively correlated with BMI $(r=0.314$ and $p=0.005)$ and lean body mass $(r=0.343$ and $p=0.007)$.

Ghrelin levels were significantly lower in the overall patient group as compared to the control group $(p=0.003)$. In subgroup analysis, only the difference between Group 2 (BMI: $20-25 \mathrm{~kg} / \mathrm{m}^{2}$ ) and control group ( $p=0.007$ ) was significant. 
With regard to the correlations between pulmonary function tests and body composition, endocrine and biochemical parameters in COPD patients (Table 3 ), a positive correlation was determined between $\mathrm{FEV}_{1}(\%)$ and $\mathrm{BMI}(\mathrm{r}=0.259$ and $\mathrm{p}=0.046)$ (Figure 1 ) and leptin levels $(r=0.284$ and $p=0.028)$.

Table 1. Demographic and functional characteristics of COPD patients

\begin{tabular}{|c|c|c|c|}
\hline & $\begin{array}{c}\text { COPD } \\
\text { mean } \pm S D\end{array}$ & $\begin{array}{l}\text { Control } \\
\text { mean } \pm \text { SD }\end{array}$ & $p$ \\
\hline Male/Female (n) & $57 / 3$ & $18 / 2$ & 0.424 \\
\hline Age (years) & $60.83 \pm 6.59$ & $58.4 \pm 5.81$ & 0.146 \\
\hline $\begin{array}{l}\text { History of smoking } \\
\text { (pack.year) }\end{array}$ & $44.66 \pm 17.58$ & 0 & 0.0001 \\
\hline BMI $\left(\mathrm{kg} / \mathrm{m}^{2}\right)$ & $24.06 \pm 5.36$ & $24.48 \pm 2.05$ & 0.735 \\
\hline LBM (kg) & $54.29 \pm 8.2$ & $57.35 \pm 6.94$ & 0.140 \\
\hline LBMI $\left(\mathrm{kg} / \mathrm{m}^{2}\right)$ & $18.89 \pm 2.4$ & $20.24 \pm 1.58$ & 0.024 \\
\hline $\mathrm{FEV}_{1} \%$ & $37.80 \pm 9.53$ & $90.70 \pm 14.11$ & 0.0001 \\
\hline FRC \% & $116.78 \pm 34.27$ & $95.70 \pm 22.24$ & 0.012 \\
\hline $\mathrm{IC}(\mathrm{L})$ & $1.70 \pm 0.48$ & $2.63 \pm 0.76$ & 0.0001 \\
\hline RV/TLC (\%) & $53.13 \pm 11.38$ & $34.75 \pm 6.10$ & 0.0001 \\
\hline $\mathrm{PaO}_{2}(\mathrm{mmHg})$ & $73.69 \pm 12.99$ & $87.20 \pm 12.53$ & 0.0001 \\
\hline Leptin (ng/mL) & $2.32 \pm 1.52$ & $3.93 \pm 1.05$ & 0.001 \\
\hline Adiponectin $(\mu \mathrm{gr} / \mathrm{mL})$ & $8.52 \pm 4.46$ & $8.74 \pm 2.34$ & 0.840 \\
\hline Ghrelin (pg/mL) & $25.32 \pm 17.22$ & $43.47 \pm 27.07$ & 0.003 \\
\hline TNF-alpha (pg/mL) & $16.65 \pm 28.62$ & $19.3 \pm 18.28$ & 0.693 \\
\hline Prealbumin (g/L) & $0.33 \pm 0.68$ & $0.25 \pm 0.07$ & 0.588 \\
\hline Transferrin (g/L) & $2.78 \pm 0.76$ & $2.77 \pm 0.38$ & 0.916 \\
\hline CRP (mg/L) & $5.14 \pm 5.59$ & $7.49 \pm 7.36$ & 0.138 \\
\hline Albumin (g/dL) & $4.05 \pm 0.46$ & $4.12 \pm 0.35$ & 0.562 \\
\hline \multicolumn{4}{|c|}{$\begin{array}{l}\text { CRP: C-reactive protein; FEV1: forced expiratory volume in one second; FRC: func- } \\
\text { tional residual capacity; IC: inspiratory capacity; COPD: chronic obstructive pulmo- } \\
\text { nary disease; RV: residual volume; SD: standard deviation; TLC: total lung capacity; } \\
\text { TNF-alpha: tumour necrosis factor- alpha; BMI: body mass index; LBM: lean body } \\
\text { mass; LBMI: lean body mass index }\end{array}$} \\
\hline
\end{tabular}

While inspiratory capacity (IC) was positively correlated with lean body mass $(r=0.309$ and $p=0.016)$, leptin $(r=0.338$ and $p=0.008)$, and adiponectin ( $r=0.401$ and $p=0.002$ ) levels (Figure 2,3 ), a negative correlation was determined with TNF-alpha $(r=-0.356$ and $p=0.005)$. There was also a negative correlation between total lung capacity and TNF-alpha $(r=-0.323$ and $p=0.012)$.

When the patients were evaluated with regard to hyperinflation, no difference was observed in terms of BMI, lean body mass, leptin, adiponectin, ghrelin, TNF-alpha, prealbumin, transferrin and CRP levels between patient groups with FRC (\%) >120 and with FRC (\%) $<120$ (Table 4).

\section{DISCUSSION}

The present study investigated the relation of body composition changes with endocrine and systemic inflammatory parameters (leptin, adiponectin, ghrelin, TNF-alpha), and pulmonary functions in

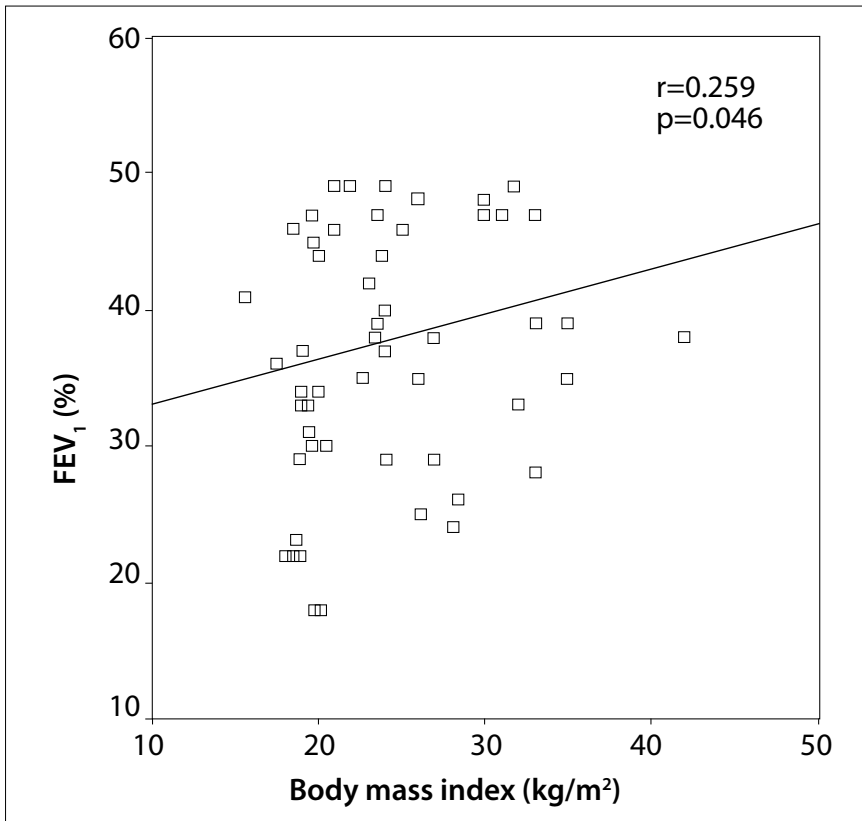

Figure 1. Positive correlation was determined between $\mathrm{FEV}_{1}(\%)$ and body mass index $(r=0.259$ and $p=0.046)$.

Table 2. Comparison of biochemical and endocrine parameters between COPD patients according to their body mass index

\begin{tabular}{|c|c|c|c|c|c|}
\hline & $\mathrm{BMI}<20($ mean \pm SD $)$ & BMI: $20-25($ mean \pm SD) & $\mathrm{BMI}>25($ mean \pm SD) & Control (mean \pm SD) & $p$ \\
\hline FBG (mg/dL) & $93.00 \pm 10.12$ & $93.05 \pm 11.98$ & $98.70 \pm 10.08$ & $94.60 \pm 9.73$ & 0.281 \\
\hline Leptin (ng/mL) & $0.93 \pm 0.46$ & $4.73 \pm 3.86$ & $5.66 \pm 9.23$ & $1.93 \pm 1.48$ & $<0.001$ \\
\hline Adiponectin $(\mu \mathrm{gr} / \mathrm{mL})$ & $7.07 \pm 2.39$ & $8.11 \pm 4.16$ & $10.39 \pm 5.73$ & $8.74 \pm 2.35$ & 0.064 \\
\hline Ghrelin (pg/mL) & $31.37 \pm 19.21$ & $20.01 \pm 12.72$ & $24.59 \pm 17.94$ & $43.47 \pm 27.07$ & 0.002 \\
\hline TNF-alpha (pg/mL) & $27.57 \pm 46.50$ & $8.81 \pm 4.07$ & $13.57 \pm 12.89$ & $19.36 \pm 18.28$ & 0.089 \\
\hline Prealbumin (g/L) & $0.23 \pm 0.07$ & $0.24 \pm 0.06$ & $0.53 \pm 1.17$ & $0.25 \pm 0.07$ & 0.301 \\
\hline Transferrin $(\mathrm{g} / \mathrm{L})$ & $2.93 \pm 0.72$ & $2.85 \pm 0.60$ & $2.58 \pm 0.94$ & $2.77 \pm 0.38$ & 0.987 \\
\hline CRP (mg/L) & $6.52 \pm 7.43$ & $4.91 \pm 5.54$ & $3.99 \pm 2.81$ & $7.49 \pm 7.36$ & 0.447 \\
\hline Albumin (g/dL) & $3.88 \pm 0.50$ & $4.22 \pm 0.35$ & $4.07 \pm 0.47$ & $4.12 \pm 0.35$ & 0.562 \\
\hline
\end{tabular}




\begin{tabular}{|c|c|c|c|c|c|c|c|c|c|c|c|c|c|c|}
\hline & $\mathbf{r}$ & $p$ & $\mathbf{R}$ & $p$ & $r$ & $p$ & $r$ & $p$ & $r$ & $p$ & $r$ & $\mathbf{p}$ & $r$ & $p$ \\
\hline $\mathrm{BMI}\left(\mathrm{kg} / \mathrm{m}^{2}\right)$ & .259 & .046 & .046 & .727 & .008 & .954 & -.038 & .775 & .014 & .917 & .248 & .056 & -.171 & .192 \\
\hline LBM (kg) & .232 & .074 & .107 & .417 & -.051 & .699 & -.036 & .787 & -.014 & .915 & .309 & .016 & -.225 & .084 \\
\hline Ghrelin (pg/mL) & -.097 & .462 & -.060 & .650 & -.078 & .555 & -.035 & .790 & -.033 & .805 & -.145 & .262 & .053 & .687 \\
\hline TNF-alpha (pg/mL) & -.101 & .443 & -.323 & .012 & -.161 & .220 & -.245 & .059 & -.167 & .202 & -.356 & .005 & -.137 & .295 \\
\hline Prealbumin (g/L) & -.044 & .739 & .156 & .235 & .070 & .596 & .145 & .269 & .134 & .308 & -.042 & .748 & .68 & .608 \\
\hline
\end{tabular}

CRP: C-reactive protein; FEV $_{1}$ : forced expiratory volume in one second; IC: inspiratory capacity; RV: residual volume; TLC: total lung capacity; TNF-alpha: tumour necrosis factoralpha; BMI: body mass index; LBM: lean body mass

Table 4. Comparison of body composition, endocrine and biochemical parameters according to the presence of hyperinflation

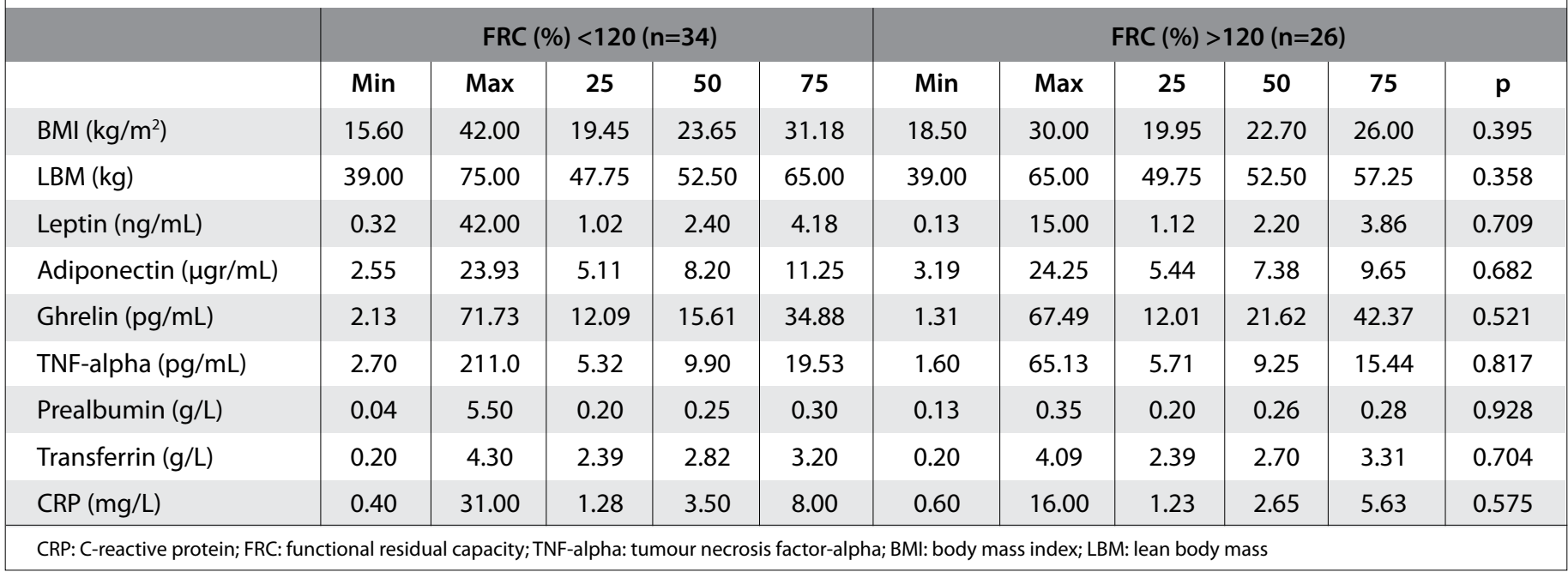

stable COPD patients. A weak positive correlation was determined between body mass index and airway obstruction, whereas a moderate positive correlation was determined between lean body mass and inspiratory capacity. Leptin and ghrelin levels were found to be significantly lower in patients with COPD. However, no statistically significant difference was determined in terms of TNF-alpha, CRP, prealbumin and transferrin levels.

Leptin is a hormone secreted from adipocytes and basically plays a role in energy consumption, weight regulation through control of appetite and energy balance. In addition, leptin is a proinflammatory cytokine (11). Reduction in food intake, increase in energy utilization and decrease in body weight have been observed after administration of recombinant leptin in rats with a genetic defect in leptin production. Luo et al. (12) found that BMI, body fat ratio, plasma ghrelin and leptin levels were lower, but TNF-alpha and CRP levels were higher in COPD cases as compared to healthy individuals.

A study that evaluated TNF-alpha and leptin levels and related parameters in COPD patients without weight loss found that leptin levels were increased in patients having a COPD attack, but lower in stable COPD patients versus control group with no statistical difference determined (13). In another study serum leptin levels were found to be low in COPD patients with a low BMI (14). Moreover, it was claimed that weight loss in COPD patients does not cause an increase in leptin levels, but contrarily leptin remain at certain levels as a compensatory mechanism to preserve lean body mass in COPD patients (14).

In the present study, although plasma leptin levels were decreased in COPD patients as compared to the control group, BMI subgroup analysis revealed that plasma leptin levels were lower in patients with weight loss $\left(\mathrm{BMI}<20 \mathrm{~kg} / \mathrm{m}^{2}\right.$ ) but higher in the other patient groups (BMI $\geq 20 \mathrm{~kg} / \mathrm{m}^{2}$ ). In addition, plasma leptin levels in COPD patients were correlated with BMI, lean body mass, FEV and IC. Similar to our results, Eker et al. (15) as well found leptin levels to be lower in the COPD group versus the control group, and determined a positive correlation between leptin levels and BMI. These results suggest that leptin levels are lower in patients with progressive airway obstruction, and decreased inspiratory capacity in other words with enhanced hyperinflation, and that decreased plasma leptin levels might be 

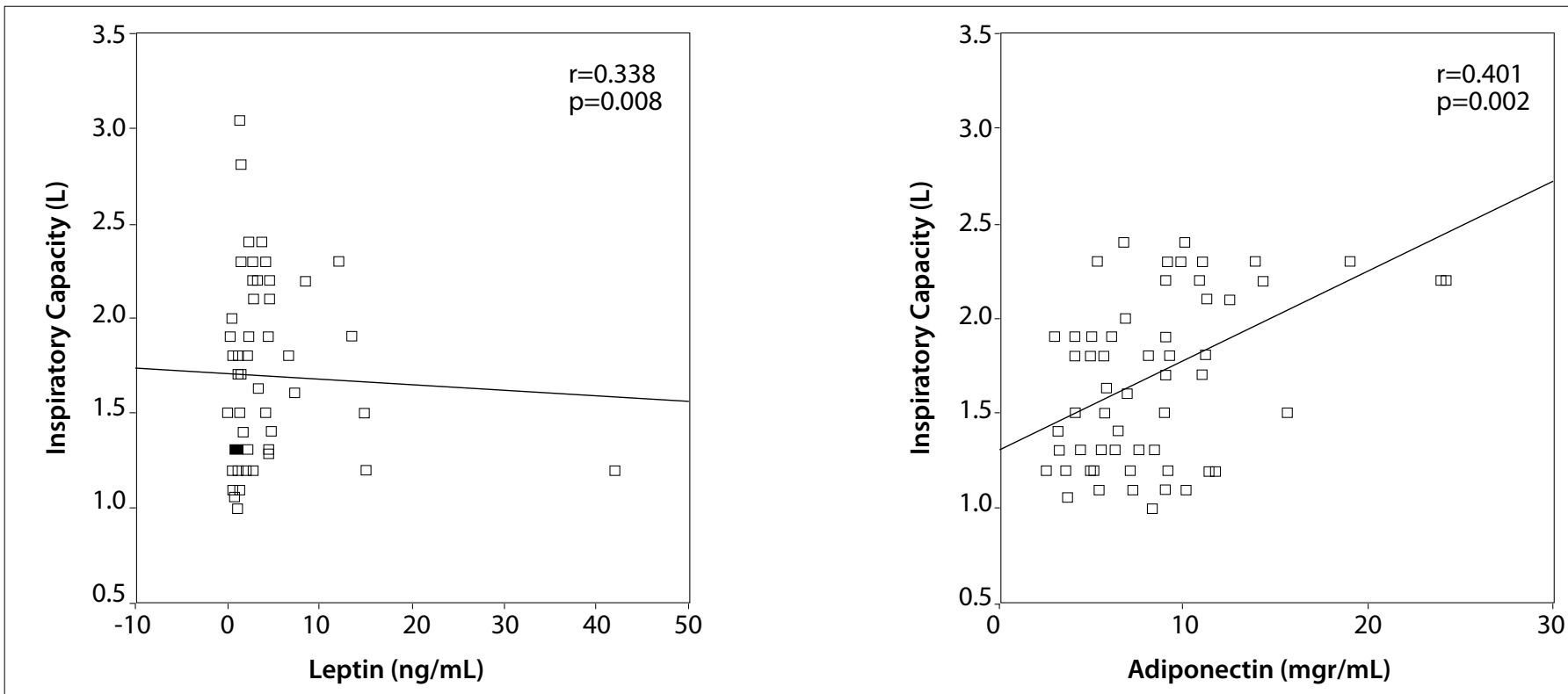

Figure 3. a, b. Positive correlation was determined between inspiratory capacity and leptin ( $r=0.338$ and $p=0.008)$ concentration (a). Positive correlation was determined between inspiratory capacity and adiponectin ( $r=0.401$ and $p=0.002)$ concentration (b).

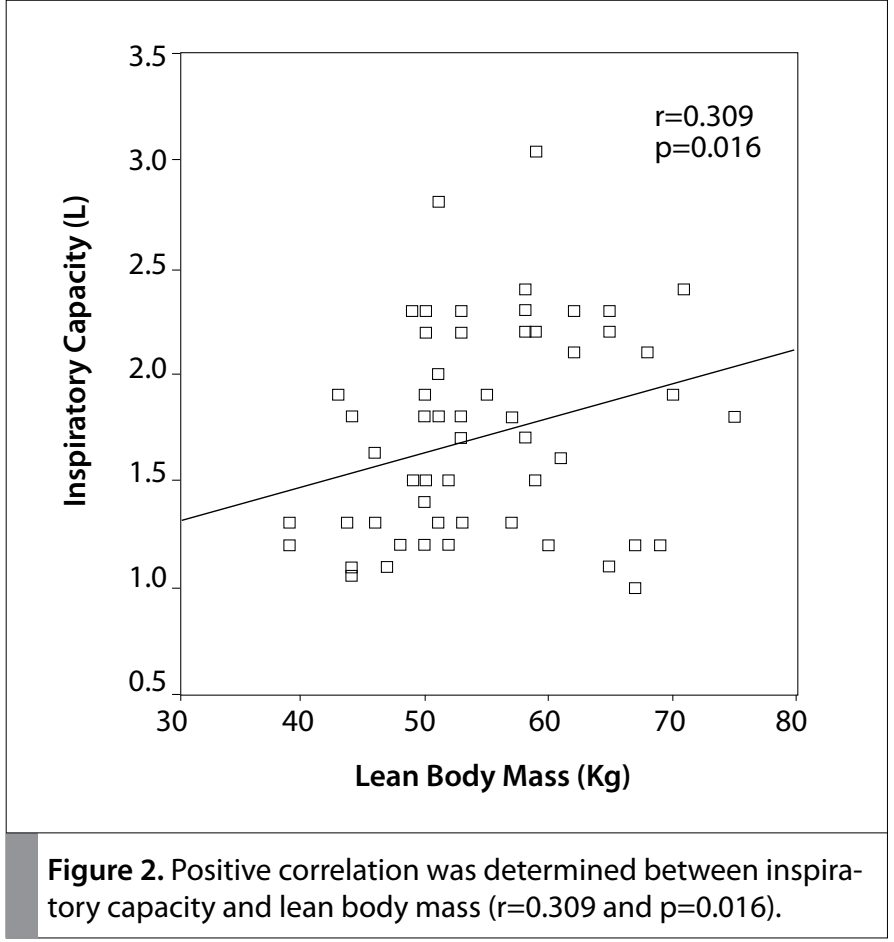

associated with a decrease in body mass index and lean body mass. In addition, it supports the notion that weight loss in COPD patients does not lead to an increase in circulating leptin levels but contrarily leptin remains at certain levels as compensatory mechanism to preserve lean body mass in COPD patients (14).

Ghrelin is called as endogenous growth hormone (GH)-related peptide and is secreted from the gastric mucosa. Ghrelin stimulates $\mathrm{GH}$ secretion and enables positive energy balance. In the literature, there is limited number of studies on ghrelin. In a study performed in Japan, patients were assigned to two groups (BMI $\geq 20$ and $\mathrm{BMI}<20$ ), and serum ghrelin, TNF, IL- 6 and norepinephrine concentrations were found to be significantly higher in the group with a low weight. Subgroup analysis revealed higher plasma ghrelin levels in the group with low weight compared to the group with normal weight. Plasma ghrelin levels were found to be directly proportional to residual volume (RV) and residual volume/total lung capacity (RV/TLC). As a result, they defended that plasma ghrelin levels were increased in low-weight COPD patients and that high levels were associated with abnormal pulmonary functions and cachectic state (16). In the present study, while serum ghrelin levels were lower in the COPD patient group in comparison to the control group, subgroup analysis revealed that the difference arouse from Group 2 (BMI: 20-25) an Group 3 (BMI >25). No relation was determined between pulmonary function tests and ghrelin levels. It is accentuated that abnormal ghrelin activity might cause overweight or low weight (17).

Adiponectin is an adipocyte-specific protein, secreted from visceral adipose tissue and has anti-inflammatory, anti-atherosclerotic and anti-obesity effects. In a study, adiponectin levels were found to be significantly higher in normal-weight COPD patients in comparison to healthy individuals and determined a positive correlation between serum adiponectin levels and residual volume (18). In the present study, no difference was observed between COPD patients and the control group in terms of adiponectin levels but subgroup analysis demonstrated statistically significantly lower adiponectin levels in the group with a $\mathrm{BMI}<20$ in comparison to the group with a BMI $>25(p=0.031)$. Furthermore, serum adiponectin levels were positively correlated with $\mathrm{BMI}(\mathrm{r}=0.314$ and $\mathrm{p}=0.005)$ and lean body mass $(r=0.343$ and $p=0.007)$, as well as between inspiratory capacity and serum adiponectin levels ( $r=0.401$ and $p=0.002$ ). Although these results suggest that serum adiponectin levels decrease with hyperinflation and low BMI in COPD patients, it is disputable.

In the previous studies, serum TNF-alpha levels were found to be higher in COPD patients as compared to healthy controls $(5,12,13,18)$. In addition, it was also demonstrated that TNF-alpha levels were higher in slim subjects as compared to subjects with normal-weight (18). 
In another study performed in 2006, no significant difference was observed between stable COPD patients with and without malnutrition in terms of serum TNF-alpha levels and, in addition, no correlation was determined between leptin and TNF-alpha levels (19). In the present study, serum TNF-alpha levels in COPD patient group was not found to be different from that in the control group; however, subgroup analysis revealed higher TNF-alpha levels in the COPD patient group with low-weight $\left(\mathrm{BMI}<20 \mathrm{~kg} / \mathrm{m}^{2}\right)$ with no statistical significant difference determined. The negative correlation between TNF-alpha levels and IC suggests that the serum levels of TNF alpha increase in parallel with the progression of disease and development of hyperinflation.

With regard to lung volumes, no relation was found between hyperinflation (FRC $>120 \%$ ), and weight loss or biochemical marker levels. However, it is a known fact that IC is decreased along with the development of hyperinflation; in the present study, IC showed a positive correlation with lean body mass $(r=0.309, p=0.016)$, leptin $(r=0.338, p=0.008)$ and adiponectin $(r=0.401, p=0.002)$, but a negative correlation with TNF-alpha $(r=0.356, p=0.005)$. These findings suggest that IC might be more valuable in monitoring patients. It remains unclear whether change in adiponectin levels is a predisposing factor for or a result of pulmonary disease. Although adiponectin levels show a positive correlation with pulmonary functions in healthy individuals, studies, in general, revealed a negative correlation in COPD patients $(20,21)$. However, the present study determined a positive correlation between adiponectin and IC in patients with COPD.

\section{CONCLUSION}

When the studies in the literature on systemic inflammation and weight loss in COPD are considered in general, it is seen that many inflammatory markers have been associated with weight loss. However, based on all these data, it appears that it remains impossible to explain weight loss clearly. Results of the present study are quite complex and disputable. Further studies are needed to be planned and conducted to understand better the reasons for weight loss in chronic obstructive pulmonary disease.

Ethics Committee Approval: Ethics committee approval was received for this study from the ethics committee of Mersin University.

Informed Consent: Written informed consent was obtained from patients who participated in this study.

Peer-review: Externally peer-reviewed.

Author contributions: Concept - C.Ö., Ö.C.; Design - C.Ö., Ö.C., L.T., E.S.Ö., S.N.A., A.I., B.T.; Supervision - C.Ö., Ö.C.; Resource - C.Ö., Ö.C.; Materials - C.Ö., Ö.C.; Data Collection\&/or Processing - C.Ö., Ö.C., L.T., H.Y.; Analysis\&/or Interpretation C.Ö., Ö.C., B.T.; Literature Search - C.Ö., Ö.C., E.S.Ö., S.N.A., H.Y.; Writing - C.Ö., Ö.C., E.S.Ö., S.N.A., L.T., A.I.; Critical Reviews - C.Ö., Ö.C., E.S.Ö., S.N.A., A.I.

Conflict of Interest: No conflict of interest was declared by the authors.

Financial Disclosure: The authors declared that this study has received no financial support.

\section{REFERENCES}

1. Global Strategy for the Diagnosis, Management and Prevention of Chronic Obstrutive Pulmonary Disease Revised 2011. Available from: URL: http:// www.goldcopd.org/uploads/users/files/GOLD2011_Summary.pdf

2. Laveneziana P, Palange P; ERS Research Seminar Faculty. Physical activity, nutritional status and systemic inflammation in COPD. Eur Respir J 2012 40: 522-9. [CrossRef]

3. Barnes PJ, Celli BR. Systemic manifestations and comorbidities of COPD (Review). Eur Respir J 2009; 33: 1165-85. [CrossRef]

4. Agusti A, Soriano JB. COPD as a systemic disease. COPD 2008; 5: 133-8. [CrossRef]

5. Gan WQ, Man SFP, Senthilselvan A, Sin DD. Review and a Meta-Analysis disease and systemic inflammation: a systematic association between chronic obstructive pulmonary disease. Thorax 2004; 59: 574-80.[CrossRef]

6. Kuźnar-Kamińska B, Batura-Gabryel H, Brajer B, Kamiński J. Analysis of nutritional status disturbances in patients with chronic obstructive pulmonary disease. Pneumonol Allergol Pol 2008; 76: 327-33.

7. Schols AM, Soeters PB, Dingemans AM, Mostert R, Frantzen PJ, Wouters $E F$. Prevalence and characteristics of nutritional depletion in patients with stable chronic obstructive pulmonary disease eligible for pulmonary rehabilitation. Am Res Dis 1993; 147: 1151-6. [CrossRef]

8. Schols AM, Wouters EF. Nutritional abnormalities and supplementation in chronic obstructive pulmonary disease. Clin Chest Med 2000; 21: 753-62. [CrossRef]

9. Wagner PD. Possible mechanisms underlying the development of cachexia in COPD. Review. Eur Respir J 2008; 31: 492-501. [CrossRef]

10. Wagner J, Clausen JL, Coates A, Pedersen OF, Brusasco V, Burgos F, et al. ATS/ERS task force: standardization of the measurement of lung volumes. Eur Respir J 2005; 26: 511-22. [CrossRef]

11. Lago F, C Dieguez, Gómez-Reino J, Gualillo O. Adipokines as emerging mediators of immune response and inflammation. Nat Clin Rheumatol 2007; 3: 716-24. [CrossRef]

12. Luo FM, Liu XJ, Li SQ, Wang ZL, Liu CT, Yuan YM. Circulating ghrelin in patients with chronic obstructive pulmonary disease. Nutrition 2005; 21: 793-8. [CrossRef]

13. Calikoglu M, Sahin G, Unlu A, Ozturk C, Tamer L, Ercan B, et al. Leptin and TNF-Alpha levels in patients with chronic obstructive pulmonary disease and their relationship to nutritional parameters. Respiration 2004; 71:44-50.

14. Karakas S, Karadag F, Karul AB, Gurgey O, Gurel S, Guney E, et al. Circulating leptin and body composition in chronic obstructive pulmonary disease. Int J Clin Pract 2005; 59: 1167-70. [CrossRef]

15. Eker S, Ayaz L, Tamer L, Ulubas B. Leptin, visfatin, insulin resistance, and body composition change in chronic obstructive pulmonary disease. Scand J Clin Lab Invest 2010; 70: 40-4. [CrossRef]

16. Itoh T, Nagaya N, Yoshikawa M, Fukuoka A, Takenaka H, Shimizu Y, et al. Elevated plasma ghrelin level in underweight patients with chronic obstructive pulmonary disease. Am J Respir Crit Med 2004; 170: 879-82. [CrossRef]

17. Özkan S, Çaylak E. Grelin ve biyokimyasal fonksiyonları. Türkiye Klinikleri Tıp Bilimleri Dergisi 2006; 26: 272-83.

18. Tomoda K, Yoshikawa M, Itoh T, Tamaki S, Fukuoka A, Komeda K, et al. Elevated plasma adiponectin in underweight patients with chronic obstructive pulmonary disease. Chest 2007; 132: 135-40. [CrossRef]

19. Yang-Yi M, Sun-Tie Y. The role of serum leptin and tumor necrosis factor in malnutrition of male chronic obstructive pulmonary disease patients. Chin Med J 2006; 119: 628-33.

20. Garcia P, Sood A. Adiponectin in pulmonary disease and critically ill patients. Curr Med Chem 2012; 19: 5493-500. [CrossRef]

21. Ali Assad N, Sood A. Leptin, adiponectin and pulmonary diseases. Biochimie 2012; 94: 2180-9. [CrossRef] 